\title{
Zapping rocks on Mars: exploring the Red Planet with Curiosity and its laser (Presentation Video)
}

\section{Roger Wiens}

Roger C. Wiens, "Zapping rocks on Mars: exploring the Red Planet with Curiosity and its laser (Presentation Video)," Proc. SPIE 8860, UV/Optical/IR Space Telescopes and Instruments: Innovative Technologies and Concepts VI, 88601E (23 October 2013); doi: 10.1117/12.2050969

EDIE Event: SPIE Optical Engineering + Applications, 2013, San Diego, California, United States 


\title{
Zapping Rocks on Mars: Exploring the Red Planet with Curiosity and its Laser (Presentation Video)
}

\author{
Roger C. Wiens, Los Alamos National Lab. (United States)
}

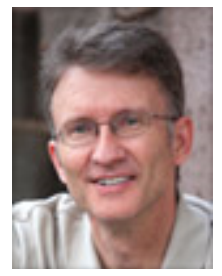

\begin{abstract}
When the one-ton Curiosity Rover landed on Mars in 2012, one of the ten instruments was a joint French and US-built laser remote sensing device. ChemCam ablates small amounts of rock and soil up to 25 feet away to determine their compositions by observing the plasma emission from a minute $0.5 \mathrm{~mm}$ analysis footprint. This "LIBS" technique provides semi-quantitative compositions with sensitivity to nearly every element in the periodic table, and with the important abilities to blast dust away prior to a rock analysis and to perform depth profiles with successive shots in one spot. Over 40,000 spectra have been returned in the first seven months of the mission. The talk will describe ChemCam and give an overview of the initial part of Curiosity's mission.
\end{abstract}

View presentation video on SPIE's Digital Library: http://dx.doi.org/10.1117/12.2050969 